\title{
Erratum
}

\section{Rawls and the Forgotten Figure of the Most Advantaged: In Defense of Reasonable Envy toward the Superrich-ERRATUM}

\section{JEFFREY EDWARD GREEN}

\author{
doi:10.1017/S0003055412000585, Published online by Cambridge University, Press 24 January 2013.
}

$\mathbf{T}$ he version of Figure 1 on page 127 of the article by Green in the February 2013 issue of American Political Science Review is a redrawing of the an image in a book by Rawls (2001) rather than the original. In addition, owing to an oversight, the permission line is not included in the figure legend. The original figure, as it appeared in the book by Rawls, and the legend with the permission line appear below.

FIGURE 1. "In this figure the distances along the two axes are measured in terms of an index of primary goods, with the $x$-axis the more advantaged group (MAG), the $y$-axis the less advantaged (LAG). The line JJ parallel to the $x$-axis is the highest equal-justice line touched by the OP curve at its maximum at $D$. Note that $D$ is the [Pareto] efficient point nearest to equality, represented by the 45-degree line. $N$ is the Nash point, where the product of utilities is maximized (if we assume utilities to be linear in indexes of primary goods) and $B$ is the Bentham point, where the sum of individual utilities is maximized again with the same assumption). The set of [Pareto] efficient points goes from $D$ to the feudal point $F$, at which the OP curve becomes vertical... Society aims, other things equal, to reach the highest equal-justice line measured by the distance from $\mathrm{O}$ along the 45-degree line. To do this it moves as far northeast as possible along the OP curve and stops when this curve bends to the southeast" ( $R, 62$, emphasis added). Reprinted by permission of the publisher from Justice as Fairness: $\boldsymbol{A}$ Restatement, by John Rawls, p. 62. Cambridge, Mass.: The Belknap Press of Harvard University Press $(\odot) 2001$ by the President and Fellows of Harvard College.

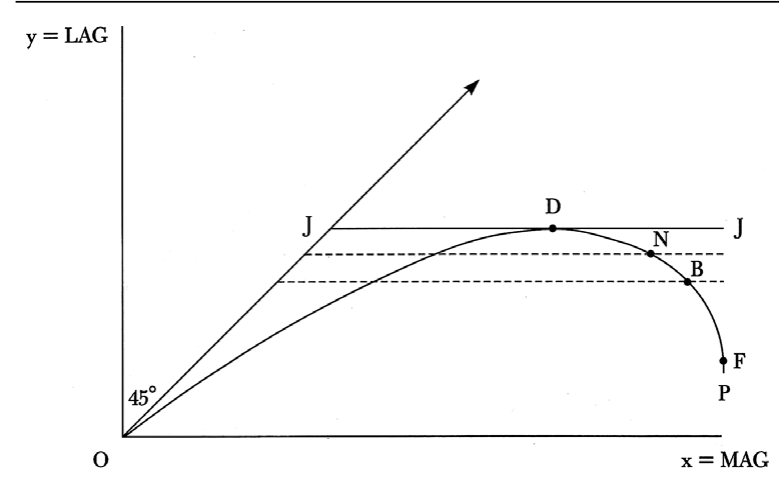

We regret the error.

\section{REFERENCES}

Green, J. E. 2013. "Rawls and the Forgotten Figure of the Most Advantaged: In Defense of Reasonable Envy toward the Superrich." American Political Science Review 107 (1): 123-38. doi:10.1017/S0003055412000585.

Rawls, John. 2001. Justice as Fairness: A Restatement [R]. Cambridge, MA: Harvard University Press. 